\title{
Impact of Aircraft Noise on Health
}

\author{
Sarah Benz $₫$, Julia Kuhlmann $(\mathbb{1}$, Sonja Jeram $₫$, Susanne Bartels $₫$,

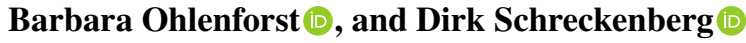

\begin{abstract}
Aircraft noise exposure is an environmental stressor and has been linked to various adverse health outcomes, such as annoyance, sleep disturbance, and cardiovascular diseases. Aircraft noise can trigger both psychological (annoyance and disturbance) and physiological stress responses (e.g. activation of the cardiovascular system and release of stress hormones). People are usually able to deal with this kind of stressor. However, a constant exposure to aircraft noise can cause a continuous state of stress. This in turn can constrain a person's ability to regenerate and restore its resources to cope with the noise situation. As a consequence, the risk for certain negative health outcomes can be increased. Within the ANIMA project, literature reviews on the effects of aircraft noise on health outcomes have been performed.
\end{abstract}

Explaining how far recent works from WHO and beyond showed that noise-induced annoyance and awakening are likely to mediate to more severe health impact

S. Benz $(\bowtie) \cdot J$. Kuhlmann · D. Schreckenberg

ZEUS GmbH, Centre for Applied Psychology, Environmental and Social Research, Sennbrink 46, 58093 Hagen, Germany

e-mail: benz@zeusgmbh.de

J. Kuhlmann

e-mail: kuhlmann@zeusgmbh.de

D. Schreckenberg

e-mail: schreckenberg@zeusgmbh.de

S. Jeram

National Institute of Public Health (NIJZ), Environmental Health, Trubarjeva 2, 1000 Ljubljana, Slovenia

e-mail: sonja.jeram@nijz.si

S. Bartels

Sleep and Human Factors Research, Institute of Aerospace Medicine, German Aerospace Center (DLR e.V.), Linder Höhe, 51147 Cologne, Germany

e-mail: Susanne.Bartels@dlr.de

B. Ohlenforst

Royal Netherlands Aerospace Centre NLR, Anthony Fokkerweg 2, 1059 CM Amsterdam, The Netherlands

e-mail: Barbara.Ohlenforst@nlr.nl 
This chapter gives an overview of the relevant health outcomes affected by aircraft noise and summarises the results of different reviews and studies on these outcomes. Additionally, the underlying mechanisms of how noise impacts health are explained for daytime as well as night-time aircraft noise exposure (i.e. while sleeping). Further, the relevance of considering not only the general population, but vulnerable groups as well (such as children and elderly people) is described. Lastly, open questions for further studies are presented and discussed.

Keywords Aircraft noise exposure $\cdot$ Health outcomes $\cdot$ Noise annoyance $\cdot$ Sleep disturbance $\cdot$ Cardiovascular diseases $\cdot$ Mechanism $\cdot$ Stress

\section{What Are the Health Impacts of Aircraft Noise Exposure}

Aircraft noise exposure has been associated with various adverse health outcomes. In the ANIMA project the impact of aircraft noise on human health and well-being was reviewed for several health outcomes: cardiovascular diseases, sleep disturbance, annoyance, cognition, mental health, hearing impairment and other adverse effects, including adverse birth effects and metabolic diseases. Together, these are the critical and important health outcomes affected by environmental noise as mentioned by the World Health Organisation's (WHO) Environmental Noise Guidelines for the European Region [76]. Within the ANIMA project a literature review was carried out, including publications after the year 2014. We focused on very recent articles as earlier publications are already evaluated by the WHO (see https://www.mdpi. com/journal/ijerph/special_issues/WHO_reviews). The outcomes from the literature review are published in the report 'Recommendations on noise and health (Deliverable D2.3, [41]).

The WHO reviews as well as the ANIMA literature review demonstrate associations between long-term aircraft noise exposure and ischemic heart disease, annoyance, reading and oral comprehension in school children as well as sleep disturbance during the night. In the ANIMA review, associations were made between sleep disturbance, annoyance and certain long-term health outcomes, indicating that self-reported sleep disturbance and annoyance may be mediators of adverse health outcomes. In the following sections new findings on the effects of aircraft noise exposure on different health outcomes are summarised.

\section{Cardiovascular Diseases}

Several cardiovascular health effects were investigated, such as hypertension (high blood pressure), ischaemic heart disease (coronary artery disease) and stroke. New studies show that aircraft noise exposure may increase the risk of hypertension, especially if exposure is high during the night time. Evidence on heart diseases needs 
cautious interpretation and further research. It was not shown that an increased risk for stroke is associated with increased aircraft noise exposure. The lack of statistical significance could be related to the small number of persons which are exposed to the highest levels of aircraft noise. The studies investigated either the prevalence or the incidence of diseases associated with aircraft noise exposure. Prevalence describes the occurrence of a disease in a higher aircraft noise exposed population relative to the occurrence of the disease in a less exposed population. The aircraft noise induced incidence of a disease, however, refers to the occurrence of new cases of this disease in a high exposed population compared to new cases in an unexposed or less exposed population.

\section{Circulatory System and Hypertensive Heart Diseases}

The WHO review did not show a significant increase of the risk for hypertension associated with increased aircraft noise exposure. However, such risk was confirmed in case of road traffic noise [76]. The ANIMA literature review included ten publications on the circulatory system and hypertensive diseases.

The exposure to aircraft noise at night was frequently included in new studies of the circulatory system and hypertensive heart diseases. An association between the risk of hypertension and exposure to night-time aircraft noise reached $34 \%$ increase related to $10 \mathrm{~dB}$ increase in $L_{\text {night }}$. Additionally, two recent studies show a significant impact of aircraft noise on hypertensive heart disease. The importance of exposure during the night is evident $[58,59]$. However, even when significantly increased risk for hypertension incidence was observed for individuals exposed to aircraft noise at levels of 50-54 dB LAeq24h the conclusion in a large case-control study was that there is no association between air traffic noise and hypertension [77].

Overall, new studies show and confirm the WHO statement on the association between aircraft noise and hypertension and add evidence on the importance of also considering the night-time noise exposure. Studies with additional methodological improvements would be needed to further reduce inconsistencies and improve the quality. Still, the findings of new cohort studies seem to point toward a harmful effect caused by aircraft noise exposure [29].

\section{Ischaemic Heart Disease and Other Forms of Heart Diseases}

The WHO review showed a significant but small increased risk for ischaemic heart disease incidence associated with increased aircraft noise exposure [76]. The ANIMA review included five publications on ischaemic heart diseases, myocardial infarction, cardiac arrhythmia and heart failure.

New studies use different approaches to examine the association between aircraft noise exposure and the occurrence of a disease. For example, different noise indicators were considered such as the intermittency ratio. The intermittency ratio, which is a noise parameter that describes how strongly a noise event emerges from the 
background, at night showed stronger relation to myocardial infarction hazard than continuous noise levels of the same average level. With respect to myocardial infarction, the most sensitive time of noise exposure was between 5.00 and 6.00 a.m. However, this was not confirmed by other researchers. Another approach is to use the mortality rate ratio (MRR). The MRR from cardiovascular disease resulted in an increase of $18 \%$ per $10 \mathrm{~dB}$ of the overall day exposure $L_{\mathrm{den}}$ to aircraft noise. For coronary heart disease and myocardial infarction, the MRR increased with $24 \%$ and $28 \%$ per $10 \mathrm{~dB}$, respectively, and was higher for men compared to women [23]. For other forms of heart disease, an arrhythmia was observed during the night and heart failure or hypertensive heart disease was reported to be associated with aircraft noise exposure.

The association observed between aircraft noise exposure and risk of myocardial infarction or mortality from ischaemic heart disease or other forms of heart diseases needs cautious interpretation. The heart diseases are all in all multi-factorial determined and the impact of aircraft noise is relatively small. However, it becomes relevant given that in a population even health effects of small size sum up to a considerable number of people suffering from severe health problems.

\section{Stroke}

The WHO review did not show a significant increase of risk for stroke associated with increased aircraft noise exposure [76]. The ANIMA review included four publications on cerebrovascular disease including different types of stroke.

Overall, there is no conclusive evidence with respect to an association between aircraft noise exposure and stroke.

The findings of the recent Swiss National Cohort around Zurich Airport between 2000 and 2015 suggest that night-time aircraft noise can trigger acute cardiovascular mortality with a similar association found in previous studies for long-term aircraft noise exposure [58]. The RIVM review [70] and the review on aviation noise and public health [29] confirm the WHO conclusion that there is no evidence of risk for stroke associated with aircraft noise.

\section{Key Message}

Several studies on cardiovascular diseases show an association with aircraft noise exposure. However, they lack conclusive results. New studies add information on the importance of the night-time exposure to noise, and also the number and the level of individual noise events, therefore they should be considered in more detail.

\section{Sleep Disturbance}

The WHO review showed a significant increase in the probability of additional awakenings due to aircraft noise related to noise indicator $L_{\text {Smax }}$ and an increase 
in percentage of persons reporting to be highly sleep disturbed (\%HSD) in relation to noise indicator for night-time $L_{\text {night }}$ [76]. The literature review conducted within ANIMA identified 24 publications comprising journal papers as well as conference proceedings.

The vast majority of the studies refer to cross-sectional studies in the field. Three studies have undertaken a pre-post-comparison for sleep disturbance/sleep quality before and after the change of a night flight regime $[48,61,66]$. In eight publications, disturbance was assessed by physiological measurements [4, 7, 19, 37, 47, 48, 49, 63]. Twenty-one studies used self-reports to assess different sleep outcomes for aircraft noise, such as insomnia, awakenings, and sleep quality. Only six of these studies specifically referred to aircraft noise as the source for disturbance $[13,17,48,51$, 57, 60], whilst thirteen others did not [4, 7, 15, 34-37, 39, 43, 50, 56, 59, 63, 66]. Two studies applied both neutral sleep quality questions but also questions referring to aircraft noise as the source for sleep disturbance [52, 55].

Results of recent studies are generally in line with the findings of the WHO review. Physiologically measured disturbances of sleep quality, represented by an increase of the time to fall asleep and wake time, number of awakenings or increased motility were found for an increase in the exposure represented by higher average night levels or a higher number of (loud) aircraft noise events. Studies using physiological measurements confirmed the significant impact of the maximum sound pressure level on the probability for awakening reactions. In one study [63], however, results were not statistically significant, most probably due to the small sample of participants. The benefit of the implementation of a night curfew from 23:00 to 05:00 at a large German airport (Frankfurt Airport) was demonstrated with regard to the number of awakenings per night, total sleep time and also the time spent in deep sleep [48]. However, residents reported higher sleep disturbance and an increased number of awakenings in the early morning coinciding with the end of the night curfew at 05:00 [60]. Thus, the benefit of this night curfew is rather ambiguous.

A laboratory study compared the impact of the three major traffic noise sourcesair, railway and road traffic — and revealed that the probability to wake up from equal maximum levels increased in the order aircraft $<$ road $<$ railway noise. This order is reversed to that usually found for self-reported long-term sleep-disturbance, and annoyance [19].

Since the assessment of both exposure variables and sleep outcomes differed considerably between the eight studies included in this review, a comparison between results is not possible.

Effects of aircraft noise exposure were also shown for self-reported sleep disturbances, decreased sleep quality or similar sleep outcomes. Eighteen of the twentyone publications report an effect of aircraft noise on participants' self-reported sleep outcomes. Studies not showing an effect all referred to general sleep outcomes not mentioning aircraft noise as the source for sleep disturbances. The conclusion that effects of aircraft noise exposure on self-reported sleep disturbance are higher when aircraft noise was mentioned as a source for the sleep disturbances, was already drawn in the recent WHO evidence review on the impact of environmental noise on sleep [6]. The magnitude of effect also depended on the assessment methods 
for aircraft noise exposure. The magnitude of effect was enhanced in comparisons between exposure groups vs. control groups and low exposure vs. high exposure (e.g., $[38,43])$. In contrast, when aircraft noise exposure was represented by average sound pressure levels or the number of aircraft noise events during the night, not all studies revealed a significant association to sleep disturbances or sleep quality (e.g., $[37,63])$. It was concluded that average noise levels were not sufficient predictors for sleep disturbances and the number of events and maximum level should be taken into account as well. The Intermittency Ratio has been shown to be a relevant predictor of self-reported sleep disturbance and adding important information to average noise levels [13, 57].

Overall, self-reported sleep disturbance or decreased sleep quality do not necessarily reflect the physiologically measured sleep quality or sleep disturbances due to aircraft noise (e.g., [4, 48]). The studies included in this review using measures of self-reports differed considerably with regard to the assessed sleep outcomes (sleep disturbances (e.g., in Brink [13]), insomnia (e.g., in Kwak et al. [43]) etc.) and questions used for this assessment, e.g. specifically if sleep disturbances are attributed to aircraft noise in the wording of questions (e.g., in Röösli et al., [57]) or not (e.g.,in Janssen et al. [37]). Therefore, the possibility to compare the results of the various studies is limited.

\section{Key Message}

Physiological measurements reveal sleep disturbances due to aircraft noise exposure, mainly represented by awakenings. Self-reported measures of sleep outcomes are affected by aircraft noise exposure, too, but do not necessarily reflect physiologically measured sleep outcomes. The magnitude of the effect of aircraft noise exposure on sleep is influenced both by the assessment of exposure variables and sleep outcomes. Average sound pressure levels are insufficient predictors of both physiologically-measured and self-reported sleep outcomes. The number of noise events and maximum levels should be considered, too.

\section{Cognitive Impairment}

The WHO review on cognition showed that most of the studies focus on the impact of aircraft noise on children. Children exposed to aircraft noise above $55 \mathrm{~dB} L_{\mathrm{den}}$ have a higher risk of experiencing cognitive constraints related to their reading skills and oral comprehension [57]. The ANIMA review included only one new publication on cognitive impairment in children [39]. In this new study, a $20 \mathrm{dBA}$ increase in aircraft noise exposure was associated with a 2-month delay in reading abilities for the whole sample, and with a 3-month delay in the subsample of non-migrant children. For the evaluation of the noise effect, other factors impacting reading should also be considered, especially socioeconomic status and the number of books at home. 
The ANIMA review supports the WHO conclusion on the negative association between aircraft noise exposure and reading comprehension in children. The review on aviation noise and public health [29] confirms the WHO conclusions.

\section{Key message}

Aircraft noise has an effect on cognitive functioning in children related to reading skills and oral comprehension. These effects are important to be considered in protection of children's health.

\section{Mental Health and Well-Being}

In the WHO review it was emphasised that consistent conclusions for the effects of aircraft noise exposure on mental health and well-being could not be drawn. This is due to the small number of studies, the differences in the experimental design of the studies and a variation of methods for noise metrics and outcome measurements. Further, no estimates of risks could be drawn from the results [77]. In newer studies included in the ANIMA review as well as resulting from new searches there is new but still inconsistent evidence for a relationship between aircraft noise and mental health.

In studies with short-term measures of well-being and quality of life, referring to a momentary time period, higher aircraft sound levels were associated with lower levels of happiness [28] and well-being [44]. Further, small but significant effects of aircraft noise on quality of life were found in children [39] and adults [61], that is, with increasing aircraft noise levels reported quality of life decreased.

In a study on the impact of aircraft noise exposure on well-being and health in children it was shown that noise exposure had no direct effects on child-reported physical well-being and parents' reports of children's health [64].

No association was found for aircraft noise exposure and the use of medication indicated for mental health issues [10], and psychological distress measures [9]. However, in another study significant differences regarding depression scores between high exposure groups and the control group were observed [35].

In two studies examining the long-term effect of aircraft noise on diagnoses of depression no direct association was found for depression diagnoses one year later in a German study [11] and ten years later in a Swiss study [25].

Finally, for diagnoses of manifest disorders a study analysing insurance data found a positive relationship between aircraft noise exposure and diagnosed unipolar depression when socioeconomic status was taken into account, i.e. with increasing aircraft noise levels an increase in risk for diagnoses of depression was investigated [62].

Results of the ANIMA review and new literature support the findings of the initial WHO review indicating inconsistent evidence for the influence of aircraft noise on mental health outcomes. 3 of 5 studies showed weak but significant associations of quality of life and well-being measures with noise exposures showing health-related 
quality of life to be impaired by aircraft noise, while only two other studies found significant evidence for the impact of aviation noise on psychological distress [9] and diagnosed depressions [62].

However, further analyses support the assumption that there might not be a direct effect of aviation noise on mental health measures but effects may be mediated by annoyance, i.e. an increase in noise levels leads to an increase in annoyance ratings which further contributes to other health effects $[11,25]$.

\section{Key Message}

New studies are available indicating a negative effect of aircraft noise exposure on well-being, quality of life and diagnosed depression, but overall findings on mental health are still inconsistent and scarce.

\section{Hearing Impairment}

The WHO review found no evidence of an association between aircraft noise exposure and hearing impairment and tinnitus [77]. The ANIMA review has not identified new studies that would investigate the association between aircraft noise exposure and hearing impairment outcomes or tinnitus.

\section{Key Message}

There is no evidence that aircraft noise would cause hearing impairment in the general public.

\section{Adverse Birth Outcomes}

The WHO review identified a knowledge gap and a need for long-term studies on adverse birth outcomes (pre-term delivery, low birth weight and congenital anomalies) and other adverse effects from exposure to environmental noise, to inform future recommendations properly [77]. The ANIMA review did not identify any new study investigating the association between aircraft noise and adverse birth outcomes.

\section{Key Message}

There is a need for further research on the adverse birth and reproductive outcomes due to the importance of long-term morbidity that they can cause [29].

\section{Metabolic Diseases}

The WHO identified a research gap on the impact of aircraft noise exposure on metabolic diseases, which is why they could not draw firm conclusions [77]. 
The ANIMA review could only identify very few studies examining the impact of aircraft noise exposure on different metabolic diseases. Two studies found a significant increase in waist circumference per $10 \mathrm{~dB} L_{\mathrm{den}}$ increase in aircraft noise exposure.

Three studies are available analysing the relationship between aircraft noise exposure and obesity. Two of these studies found a significant association between aircraft noise exposure and an increase in waist circumference [21,54]. Results by Pyko et al. [54] further showed a significant weight gain of $0.03 \mathrm{~kg}$ per $10 \mathrm{~dB} L_{\mathrm{den}}$ increase in aircraft noise exposure. In another study, no such associations were observed between aircraft noise and adiposity markers as well as the development of obesity [27].

Three studies that looked at the impact of aircraft noise exposure on the incidence or prevalence of diabetes could be identified. Two studies did not show a significant relationship between aircraft noise and diabetes incidence and prevalence of diabetes [21, 72], whereas Eze et al. [24] describe a significant association between aircraft noise and incidence of diabetes, indicating that the risk of diabetes increases with increasing noise levels.

\section{Key Message}

Overall, there are very few studies available investigating the effect of aircraft noise exposure on metabolic diseases. Therefore, no firm conclusions can be drawn from the current evidence. More research is needed on this topic.

\section{Noise Annoyance-A Mediator of Aircraft Noise Effects on Health?}

Annoyance is one of the most studied and established effects of noise and is, therefore, often used as a noise impact measure for estimation and regulation purposes. As increasing aircraft noise exposure levels are linked to an increase in aircraft noise annoyance, it can further be hypothesised that increasing annoyance levels might contribute to other adverse health outcomes.

Annoyance as a stress response and health outcome itself is described as "a relation between an acoustic situation and a person who is forced by noise to do things he/she does not want to do, who cognitively and emotionally evaluates this situation and feels partly helpless" (Guski et al. [30], p. 525). Due to the multi-dimensional structure of annoyance with its cognitive, emotional and behavioural aspects, it might be related to, or even contribute to, various health outcomes or even to disorders.

Health outcomes can also be discussed as contributing to the manifestation of noise annoyance. The relation of noise annoyance and health outcomes thus leads to two questions: Do high ratings of annoyance play a role in the development and maintenance of diseases? Are people, who are suffering from any form of disease, more bothered, annoyed or disturbed by aircraft noise? 
New studies support an indirect role of annoyance in the relationship of aircraft noise exposure and health outcomes. That is, noise exposure influences noise annoyance, which in turn affects the health outcome. Supporting evidence for this theory results from studies on the effect of aircraft noise exposure on cardiovascular diseases, sleep outcomes, and mental health measures.

There has been a vast amount of studies on the impact of aircraft noise on cardiovascular diseases, but only few of them also examined the relationship to annoyance. Eriksson et al. [20] found the relative risk for hypertension among participants reporting annoyance to be higher than in participants who are not annoyed. This is supported by findings from Babisch et al. [2] and Baudin et al. [8]. By contrast, in a small study from Italy, no association between blood pressure and annoyance was shown [15].

A few studies showed a link between mental health and well-being-related measures and noise annoyance. Spilski et al. [64] reported indirect effects of aircraft noise on physical well-being in children via noise annoyance, i.e. with an increase in noise annoyance children's self-reported physical well-being decreased. Similarly, a higher risk for psychological distress was observed for people being extremely annoyed by noise in comparison to a lower risk for people being less annoyed [9]. Baudin et al. [10] found an association between aircraft noise annoyance and the use of anxiolytics (medication for anxiety disorders), implying a mediating role of annoyance for the link of aircraft noise exposure to mental health outcomes.

As shown earlier, aircraft noise did not have a direct effect on mental-health related quality of life [61] and diagnoses of depression [11], but in both studies an indirect effect via annoyance was found. The results suggest that aircraft noise exposure decreases mental health-related quality of life [61] and predicts the development of depression one year later [11] via noise annoyance. Both studies further indicate that there is a reciprocal association, i.e. that diagnoses of depression and poorer mental-health related quality of life also contributed to higher ratings of annoyance a year later. In addition, whereas the absolute aircraft noise level was not directly associated with mental health-related quality of life, in one of the studies [61] it turned out that the change in noise exposure due to the opening of a new runway lead directly and indirectly via noise annoyance to a poorer mental health-related quality of life. This indicates the importance of communication and engagement in airport noise management, particularly in situations of change (see also Chaps. 8 and 9).

Moreover, effects of annoyance were also observed for sleep quality [3] and physical activity [26]. Better rated sleep quality was accompanied with a lower rating of long-term aircraft noise annoyance [3], while noise annoyance was negatively associated with physical activity, i.e. higher ratings of transportation noise annoyance predicted reduced physical activity [26].

Some studies even showed signs of reversed causality, i.e. the health outcome also predicted a future increase of noise annoyance [11, 61]. This indicates that vulnerability due to physiological and/or psychological health issues may limit resources to cope with noise which can contribute to higher annoyance. 
Due to different methods to assess noise annoyance as well as different health outcomes and measures, it is difficult to draw consistent conclusions. However, evidence indicates that annoyance contributes to adverse mental health outcomes.

\section{Key Message}

Several studies showed a link between noise annoyance and various mental health outcomes. As stress responses (i.e. annoyance) are considered to be an important element in the development of some diseases it is recommended to further investigate the relationship between annoyance and health outcomes.

Overall, the reviews highlight the importance of addressing aircraft noise annoyance and sleep disturbance as the most critical outcomes. The assumption is that interventions aiming at the reduction of noise annoyance might in turn at least partly reduce negative health outcomes. Figure 1 gives a summary of the different health outcomes associated with aircraft noise exposure and depicts the underlying mechanisms and role of noise annoyance.

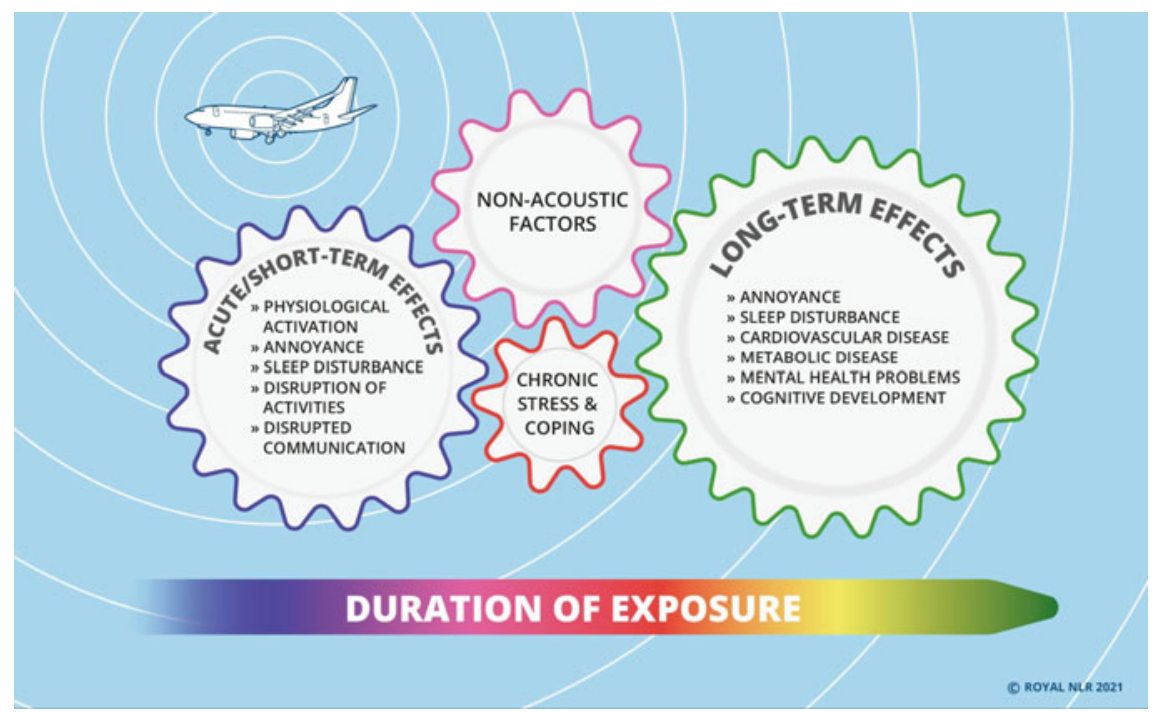

Fig. 1 Health effects of aircraft noise exposure and the role of annoyance 


\section{Why Does Aircraft Noise Exposure Have an Impact on Health?}

\section{General Health-Related Mechanisms of Aircraft Noise Exposure}

We are constantly surrounded by sound. In a general assumption, sound can be evaluated as positive, neutral, or negative. When sound is characterised as unpleasant or unwanted, the notion is changed to noise. Environmental noise can cause disturbances, e.g. in daily activities such as watching television, concentrating or in conversations with people. Further, environmental noise can be considered as an environmental stress factor that challenges the human system [12]. Stress is a reaction of the body and mind in demanding situations. In particular, stress occurs in situations of uncertainty and unpredictability [40]. Stress can be considered as a reaction in and to specific situations and stimuli, but also as a process, as stress responses can trigger subsequent reactions.

The human stress system is vital and essential to tackle demanding situations. The human body and mind always try to maintain a state of balance [16]. In case this state is threatened, the fight-or-flight response is activated, for example when confronted with a dangerous wild animal. From an evolutionary perspective, this fight-or-flight response is crucial for survival. The body shuts down current irrelevant activation (such as digestion etc.) while enhancing all acutely vital processes to stay alert and focused. Nowadays, acute life-threatening situations or stimuli are rather rare in industrial countries. However, there are other situations or stimuli that trigger this response, e.g. when environmental exposures such as noise challenge us.

In an established reaction scheme for the adverse effects of noise on health [1] the chain is described as follows: In a hierarchical chain the sound exposure leads to psychological effects in terms of cognitive, emotional and behavioural reactions (annoyance and disturbance). On a physiological level it activates physiological processes, e.g. the activation of stress hormones, that are considered as stress indicators. Prolonged physiological activation through noise can trigger biological risk factors, e.g. change in blood pressure, which are directly linked to long-term health effects [1].

An individual evaluation of the situation or stimulus further plays a key role in the stress mechanism. Psychological models suggest that for a stress response it is also important whether a situation or stimulus is perceived as demanding. A second important aspect is whether an individual feels like he/she is able to cope with the situation with the available resources [45]. Thus, when an individual feels threatened by a noise situation, the first reaction is usually trying to cope with it, e.g. by closing the windows.

As suggested by Stallen [65], coping and perceived control are essential concepts influencing the degree of annoyance. Coping is an individual's capability of having resources to deal with the noise (or other situations) that are perceived as demanding 
and being able to apply strategies. This process of coping with noise events is dynamic and is associated with reappraisals of the noise situation and the success of coping. Strategies can refer to how the noise is valued, the mindset or direct adjustments of the behaviour to the noise conditions. This can be closing the windows when the noise situation is perceived as disturbing. Coping directly relates to perceived control, which can be described as an individual's belief of being capable to influence certain events in its life. To be able to cope means that one perceives having control over the situation (and vice versa), this in turn can decrease annoyance. Hence, when one is able to cope, one experiences less stress, i.e. less annoyance (See also Chap. 8).

Furthermore, the resources to cope with demanding situations from time to time require restoration. Being in nature, having access to green areas and doing physical activities outdoors allow recovery $[18,32,31]$. Studies show that transportation noise is not only a stressor in itself, but hinders outdoor physical activities and constrains the restorative environmental qualities, thus hampering recovery from daily stress $[26,73,74]$. This means, if an environmental demand lasts over a long period of time, resources for coping decline, and restoration is constrained. Long-term stress can be harmful and the degree of annoyance can vary.

It is important to note that a physiological stress response is not independent from a psychological stress response as they are naturally linked and contribute to each other, e.g. being annoyed by noise and the release of stress hormones are reciprocally related. Further, research suggests that annoyance plays a central role in the relationship between aircraft noise exposure and health effects. In recent years, researchers have started to study annoyance as a precursor/mediator for further physical and mental health issues. That means that part of the effect of noise exposure on a health outcome is explained by the effect of noise exposure on noise annoyance, which in turn contributes to health effects (examples are described in the section on annoyance as a mediator).

Whether an individual evaluates a certain situation or stimulus as stressful, and is annoyed by it, is also determined by other factors. Acoustical features and noise characteristics (e.g. harmfulness, intensity, duration, loudness etc.) are critical when it comes to annoyance as some features can be more annoying than others, but also non-acoustical factors are crucial, e.g. attitudes, concerns, expectations etc. Their impact is elaborated on further in Chap. 8.

To summarise, noise as a stressful stimulus can affect the regulation of the human organism [16]. Short-term reactions of the stress system to noise might not be problematic. Stress responses only become unhealthy when activation of the stress system is prolonged while the resources for coping are limited. If the process of coping with noise is not successful in the long run and recovery is not possible, it is likely that this environmental demand together with the lack of control and ability to cope can lead to stress-related long-term health effects. 


\section{Health-Related Mechanisms of Aircraft Noise Exposure During Sleep}

Undisturbed sleep of sufficient length is a vital process for human beings, providing the necessary daytime alertness, performance ability and health (see [5]). According to the WHO [75], environmental noise-related self-reported sleep disturbance is widespread in the European Region leading to the highest number of noise-related loss of healthy life years compared to other noise health outcomes, followed by noise annoyance. With regard to the number of healthy life years lost in the European Union, noise-induced sleep disturbance is therefore regarded as "the most deleterious non-auditory effect of environmental noise exposure." (Basner et al. [5], p. 5). Deterioration of sleep quality and interruptions of sleep together with noise annoyance $[8,10]$ are regarded as belonging to the possible key variables in the causal pathway of noise-induced cardiovascular and metabolic diseases [77]. The consequences of interrupted sleep from transport noise can be classified as immediate reactions, short-term reactions, and long-term consequences [53, 75].

Nocturnal noise affects the human organism in a rather direct way. Even during sleep in an unconscious state, the hearing system has an alerting function to prevent harm from possible ambient threats and therefore continually inspects the environment acoustically. Sudden noise events that emerge from the background have hinted at threats in the early history of humankind. It was necessary that humans were able to awake and react quickly if necessary. Noisy events are subliminally perceived and evaluated even during sleep and can provoke physiological reactions that enhance the alertness of the individual. Therefore, meaningful noise events (e.g. one's own crying child) are more likely to cause reactions than less meaningful noise events appearing at the same sound level [6].

(a) Immediate reactions to nocturnal noise

Acute noise exposure affects the function of multiple organs and systems, including an increase in blood pressure and heart rate. These reactions are most likely induced by the release of stress hormones, such as adrenaline and noradrenaline. These reactions helped humans in their early history to react adequately to the threat, i.e. to remove the threat by actively confronting it (= fight reaction) or to flee from it (= flight reaction). These stress reactions even appear when noise is not consciously perceived, e.g. during sleep. Stress reactions due to intruding noise can disturb the balance in the organism. These changes refer to blood pressure, blood flow, blood lipids, carbohydrates (glucose) regulation, electrolytes, and thrombosis/fibrinolysis [75].

As a consequence of the above described stress responses, immediate reactions in sleeping behaviour may occur. These comprise short arousal responses, changes from a deeper to a lighter sleep stage, awakenings, body movements, and in consequence, an increase in total wake time, a reduced time in deep sleep, and more general sleep loss [75].

(b) Short-term reactions to nocturnal noise 
As a consequence of the sleep loss and the reduced restoration during the night, sleepiness in the morning and the following day and a reduced wellbeing as well as a decrease in cognitive performance during the daytime can occur [75].

(c) Long-term reactions

Chronic sleep loss and recurring interruptions of sleep are a major risk factor for cardiovascular and metabolic diseases. This link set up the assumptions that recurring noise-induced awakenings and the resulting sleep loss may account for the higher risks of negative health outcomes (see above) after a longer period of aircraft noise exposure. However, the relationship between the immediate and long-term effects of noise is not completely clear, yet, in particular as mediators such as noise annoyance seem to play a relevant role for long-term health effects as well $[8,9]$. The assumption that noise-induced sleep disturbance is part of the causal pathway from nocturnal exposure to increased risks for cardiovascular and metabolic diseases is often replicated (e.g. WHO, [76]), evidence for the mediating effect is scarce [56] or contradictory [21]. Very recently it was concluded that nocturnal aircraft noise exposure increases the risk of developing hypertension via a direct effect on blood pressure as well as via a mediated effect as a consequence of chronic sleep disturbance [56].

The appearance of acute reactions to nocturnal aircraft noise do not differ from natural reactions, such as spontaneous awakenings. However, a considerable increase in the number of these immediate reactions is assumed to constitute a health issue as it reduces the restorative power of sleep $[6,75]$. Healthy adult individuals briefly awaken approximately 20 times during an $8 \mathrm{~h}$ night and most of these awakenings are too short to be remembered the next day. Up to now, it is not clear how many additional noise-induced awakenings are needed to cause adverse effects on restoration and health. Large differences between individuals are assumed with regard to an acceptable number of additional noise-induced awakenings depending on the vulnerability of the individual towards noise effects and the presence of additional, non-acoustical risk factors for health outcomes [6]. Several vulnerability factors are discussed below.

\section{Individual Risk Factors in the Causal Chain from Noise to Health Outcomes}

The vast majority of studies included in the WHO reviews and the ANIMA review considered noise effects in the general population. Only few studies have focused on so-called vulnerable groups, who are considered as more susceptible to adverse effects of aircraft noise and at a higher than expected risk for developing particular diseases [68]. In the context of noise-induced health effects, vulnerability factors comprise physical and mental health parameters, phase in life, lifestyle factors and 
habits, educational and socioeconomic status as well as characteristics of the environment. Groups considered to be at higher risks are for instance children, elderly people, shift-workers, chronically ill including mentally ill people, noise sensitive people as well as people with a low socioeconomic status [68]. The mechanisms of the vulnerability factor are not fully understood yet and are not necessarily the same for different vulnerable groups. Children, for instance, are in a sensitive developmental life stage and do not yet possess adequate strategies to cope with the noise, although not being per se more vulnerable. They are regarded as being less annoyed than adults, having lower risks for sleep disturbances but are more susceptible for cognitive impairments and cardiovascular diseases [68]. However, recent research in primary school children showed an aircraft noise-induced reduction of deep sleep due to noise that is comparable to the deep sleep reductions due to obstructive sleep apnea syndrome [4], which is regarded as a risk factor for the development of mental, metabolic and cardiovascular dysfunctions. Elderly people are likewise not considered to be at higher risk for annoyance. But they are regarded as more susceptible to noise-induced cardiovascular dysfunctions while their susceptibility for sleep disturbance due to aircraft noise is not completely clear yet [68].

One crucial factor resulting in higher susceptibility, in particular for annoyance [46] but also for cardiovascular disease [8], psychological distress as well as psychiatric disorders [71], is noise sensitivity. Noise sensitivity has a genetic component but can also be the result of mental or physical illness [68]. Moreover, noise sensitivity has been found to be highest in middle age, attributed to a higher workload and caring for children or other family members [46]. In summary, it is concluded that future research should focus on subgroups to understand the effects and mechanisms of aircraft noise for health effects in populations at higher risks and to provide group-specific exposure response relationships. Moreover, attention should be given to potential accumulation of environmental as well as social risk factors across the lifespan but also during specific life stages resulting in higher susceptibility to noise, poorer capacities to cope with the noise and consequently to higher risks for adverse health effects. Research in this field could shed more light in starting points for intervention measures.

\section{Current Gaps in the Relationship Between Aircraft Noise Exposure and Health Outcomes}

Despite the vast amount of studies on the impacts of aircraft noise on health, a couple of open questions remain. Study results have shown the association between aircraft noise exposure and aircraft noise annoyance as well as aircraft noise induced sleep disturbances (https://www.mdpi.com/journal/ijerph/special_issues/WHO_reviews). Sleep disturbance and aircraft noise annoyance highly correlate with each other [67] and are thought to be relevant in the causal pathway from aircraft noise exposure to cardiovascular diseases [22]. However, the causal link between noise annoyance 
and sleep disturbance is still unclear, i.e. whether aircraft noise annoyance facilitates sleep disturbances or whether sleep disturbances foster aircraft noise annoyance. A reciprocal relationship between these two factors is also conceivable. That is, sleep disturbance caused by aircraft noise can cause tiredness and reduce one's resources during daytime. This in turn could contribute to aircraft noise annoyance. On the other hand, if one feels annoyed by aircraft noise, this could affect one's sleep and one is more easily disturbed by aircraft noise at bedtime. Results from one study indicate the former: a higher self-reported sleep quality was linked to lower longterm aircraft noise annoyance [3]. However, empirical evidence on this relation is still scarce.

An analysis done by Schreckenberg et al. [61] using longitudinal data from the NORAH study focused on the relationship between aircraft noise annoyance and mental health-related quality of life (HQoL) and results indicate a reciprocal relationship between these two factors. A detailed overview of studies related to annoyance and mental health is provided by van Kamp and Davies' review [69]. Overall, there are mixed results regarding a direct relationship between aircraft noise exposure and mental health. However, noise annoyance seems to be a relevant mediator. Further, Kamp and Davies [69] reviewed studies including noise sensitivity as one additional important modifying factor.

Many studies examine the relationship between aircraft noise exposure and various health outcomes, such as sleep disturbances or cardiovascular diseases. However, there are limitations in some of those studies that need further consideration and should be addressed in future studies accordingly [42]. Limitations can encompass the study design itself, including the question of causality, noise exposure assessment and outcome operationalisation, aspects concerning the response rates and the disregard of potential confounding factors (i.e. other factors that might additionally influence the health outcome).

To tackle the question of causality, i.e. whether factor A causes B or vice versa, prospective, long-term studies with (at least) two measurements should be conducted to establish a potential causal relationship. Another limitation for some studies is a selective non-response, i.e. people with certain characteristics do not participate or participate to a much lesser extent. For example, in online surveys, elderly people are often underrepresented. Aspects such as these need to be considered.

The $L_{\text {den }}$ is probably the most frequently used noise metric assessing noise exposure. However, there is a debate about whether this is always the best option to choose. Other metrics may be better suited to reflect the actual sound environment or better fit examining the research question at hand (e.g. [33]).

When looking at the relationship between noise exposure and different diseases, the operationalisation of the outcome is very important. One can rely on self-report health measures or use health data provided by insurances or other institutions that contain medical diagnoses. However, both data sources can lead to an under- and overestimation of a disease. Further, health data may lack relevant information on specific characteristics or behaviours of a person that might additionally influence the health outcome (confounding factors). 
Future studies should aim to address the above-mentioned limitations to improve data quality and generate valid and robust evidence.

\section{Conclusions}

Aircraft noise exposure poses a worldwide health issue. Literature reviews conducted by WHO and within ANIMA have identified a relationship between aircraft noise exposure and adverse health outcomes such as annoyance, sleep disturbance, and cardiovascular diseases. Further, more recent studies found evidence for an impact of aircraft noise exposure on mental health measures. It has been found that noise annoyance and sleep disturbance also play a role as mediators of adverse health effects. A continuous experience of aircraft noise annoyance has been linked to adverse health effects through stress mechanisms. Further sleep disturbance has been found to promote adverse health effects, e.g. for cardiovascular diseases. Consequently, reducing noise annoyance and sleep disturbance can help to decrease adverse health effects and to improve people's well-being and their quality of life. To reduce aircraft noise annoyance there are two important aspects. First, decreasing aircraft noise exposure should be the main focus to reduce annoyance and related health effects. Second, the possibility to recover from the noise exposure should be accomodated, e.g., by providing access to recreational and green areas and areas of reduced noise exposure [34].

The number of existing studies on the various health outcomes differs enormously. However, only a few studies are available on, e.g., metabolic diseases and as the existing results are not consistent they do not allow for drawing firm conclusions. There is an urgency for future research to further investigate the impact of aircraft noise exposure on health for different populations such as vulnerable groups like children and elderly people. As annoyance and sleep disturbance are also mediators to health outcomes, it is essential to better understand and fully identify the underlying mechanisms to efficiently minimise further adverse health effects.

Assessing noise exposure, its impact and related research results grants the evaluation of noise interventions that can be improved and harmonised after evaluation. In the WHO Environmental Noise Guidelines for the European Region [76] this is already acknowledged as for the first time the noise guidelines include recommendations on noise interventions. The systematic WHO review on the health impact of noise interventions [14] provides a study protocol to be followed in future research that allows for evaluating the impact of noise interventions. This allows for the development of proper treatment and health care, prevention of health effects and mitigation strategies. A consistent monitoring system could provide a comprehensive approach to establish how interventions affect annoyance and interrelated outcomes. With this knowledge mitigation strategies for noise annoyance can improve people's well-being as well as quality of life and mitigate potentially adverse long-term health effects. A better understanding of these underlying mechanisms and the impact of aircraft noise exposure on health can serve as an essential guidance for developing 
the specific design and targeted implementation of successful noise interventions and mitigation strategies.

\section{References}

1. Babisch W (2002) The noise/stress concept, risk assessment and research needs. Noise Health 4:1

2. Babisch W, Pershagen G, Selander J, Houthuijs D, Breugelmans O, Cadum E, Vigna-Taglianti F, Katsouyanni K, Haralabidis AS, Dimakopoulou K, Sourtzi P, Floud S, Hansell AL (2013) Noise annoyance-a modifier of the association between noise level and cardiovascular health? Sci Total Environ 452-453:50-57. https://doi.org/10.1016/j.scitotenv.2013.02.034

3. Bartels S (2014) Aircraft noise-induced annoyance in the vicinity of Cologne/Bonn AirportThe examination of short-term and long-term annoyance as well as their major determinants, Technische Universität Darmstadt.

4. Bartels S, Quehl J, Aeschbach D (2019) Effects of nocturnal aircraft noise on objective and subjective sleep quality in primary school children. In: International Congress on Acoustics (ICA), 09.-13.09.2019, Aachen, Deutschland

5. Basner M, Babisch W, Davis A, Brink M, Clark C, Janssen S et al (2014) Auditory and non-auditory effects of noise on health. Lancet 383:1325-1332

6. Basner M, McGuire S (2018) WHO environmental noise guidelines for the European region: a systematic review on environmental noise and effects on sleep. Int J Environ Res Public Health 15:519

7. Basner M, Witte M, McGuire S (2019) Aircraft noise effects on sleep: results of a pilot study near Philadelphia International Airport. Int J Environ Res Public Health 16(17):3178

8. Baudin C, Lefèvre M, Babisch W, Cadum E, Champelovier P, Dimakopoulou K, Houthuijs D, Lambert J, Laumon B, Pershagen G, Stansfeld S, Velonaki V, Hansell AL, Evrard A-S (2020) The role of aircraft noise annoyance and noise sensitivity in the association between aircraft noise levels and hypertension risk: results of a pooled analysis from seven European countries. Environ Res 19:110179. https://doi.org/10.1016/j.envres.2020.110179

9. Baudin C, Lefèvre M, Champelovier P, Lambert J, Laumon B, Evrard AS (2018) Aircraft noise and psychological ill-health: the results of a cross-sectional study in France. Int J Environ Res Public Health 15(8):1642. https://doi.org/10.3390/ijerph15081642

10. Baudin C, Lefèvre M, Babisch W, Cadum E, Champelovier P, Dimakopoulou K, Houthuijs D, Lambert J, Laumon B, Pershagen G, Stansfeld S, Velonaki V, Hansell AL, Evrard A-S (2021a) The role of aircraft noise annoyance and noise sensitivity in the association between aircraft noise levels and medication use: results of a pooled-analysis from seven European countries. BMC Public Health, 21(300). https://doi.org/10.1186/s12889-021-10280-3

11. Benz S, Schreckenberg D (2019) Examination of the causal relationship between aircraft noise exposure, noise annoyance and diagnoses of depression using structural equation modelling. In: Proceedings of the 23rd International Congress on Acoustics. Aachen, Germany

12. Bodenmann G, Gmelch S (2009) Stressbewältigung. In: Margraf J, Schneider S (Hrsg.), Lehrbuch der Verhaltenstherapie (S. 617-629). Springer Berlin Heidelberg, Berlin, Heidelberg

13. Brink M, Schäffer B, Vienneau D, Pieren R, Foraster M, Eze IC, Rudzik F, Thiesse L, Cajochen C, Probst-Hensch N, Röösli M, Wunderli JM (2019) Self-reported sleep disturbance from road, rail and aircraft noise: exposure-response relationships and effect modifiers in the SiRENE study. Int J Environ Res Public Health 16(21):4186. https://doi.org/10.3390/ijerph16214186

14. Brown AL, van Kamp I (2017) WHO environmental noise guidelines for the European Region: A systematic review of transport noise interventions and their impacts on health. Int J Environ Res Public Health 14:873. https://doi.org/10.3390/ijerph14080873

15. Carugno M, Imbrogno P, Zucchi A, Ciampichini R, Tereanu C, Sampietro G, Consonni D (2018) Effects of aircraft noise on annoyance, sleep disorders, and blood pressure among adult 
residents near the Orio al Serio International Airport (BGY). Italy La Medicina Del Lavoro 109(4):253-263

16. Chrousos GP (2009) Stress and disorders of the stress system. Nat Rev Endocrinol 5:374-381. https://doi.org/10.1038/nrendo.2009.106

17. Douglas O, Murphy E (2016) Source-based subjective responses to sleep disturbance from transportation noise. Environ Int 92-93:450-456

18. Dzhambov AM, Markevych I, Hartig T, Tilov B, Arabadzhiev Z, Stoyanov D, Gatseva P, Dimitrova DD (2018) Multiple pathways link urban green- and bluespace to mental health in young adults. Environ Res 166:223-233. https://doi.org/10.1016/j.envres.2018.06.004

19. Elmenhorst E-M, Griefahn B, Rolny V, Basner M (2019) Comparing the effects of road, railway, and aircraft noise on sleep: exposure-response relationships from pooled data of three laboratory. Studies 16(6):1073

20. Eriksson C, Bluhm G, Hilding A, Ostenson CG, Pershagen G (2010) Aircraft noise and incidence of hypertension-gender specific effects. Environ Res 110(8):764-772

21. Eriksson C, Hilding A, Pyko A, Bluhm G, Pershagen G, Östenson CG (2014) Long-term aircraft noise exposure and body mass index, waist circumference, and type 2 diabetes: a prospective study. Environ Health Perspect 122:687-694

22. Eriksson C, Pershagen G, Nilsson M (2018) Biological mechanisms related to cardiovascular and metabolic effects by environmental noise. Copenhagen: WHO Regional Office for Europe. http://www.euro.who.int/en/health-topics/environment-and-health/noise/publications/2018/ biological-mechanisms-related-to-cardiovascular-and-metabolic-effects-by-environmenta lnoise. Accessed 8 Aug 2018

23. Evrard AS, Bouaoun L, Champelovier P, Lambert J, Laumon B (2015) Does exposure to aircraft noise increase the mortality from cardiovascular disease in the population living in the vicinity of airports? Results of an ecological study in France. Noise Health 17:328-336

24. Eze IC, Foraster M, Schaffner E, Vienneau D, Heritier H, Rudzik FP, Hensch N (2017) Longterm exposure to transportation noise and air pollution in relation to incident diabetes in the SAPALDIA study. Int J Epidemiol 46(4):1115-1125

25. Eze IC, Foraster M, Schaffner E, Vienneau D, Pieren R, Imboden M, Wunderli JM, Cajochen C, Brink M, Röösli M, Probst-Hensch N (2020) Incidence of depression in relation to transportation noise exposure and noise annoyance in the SAPALDIA study. Environ Int 144:106014. https://doi.org/10.1016/j.envint.2020.106014

26. Foraster M, Eze IC, Vienneau D, Brink M, Cajochen C, Caviezel S, Héritier H, Schaffner E, Schindler C, Wanner M, Wunderli J-M, Röösli M, Probst-Hensch N (2016) Long-term transportation noise annoyance is associated with subsequent lower levels of physical activity. Environ Int 91:341-349. https://doi.org/10.1016/j.envint.2016.03.011

27. Foraster M, Eze IC, Vienneau D, Schaffner E, jeong A, Heritier H, Rudzik F, Thiesse L, Pieren R, Brink M, Cajochen C, Wunderli J, Röösli M, Probst-Hensch N (2018) Long-term exposure to transportation noise and its association with adiposity markers and development of obesity. Environ Int 121:879-889

28. Fujiwara D, Lawton RN, MacKerron G (2017) Experience sampling in and around airports, momentary subjective wellbeing, airports, and aviation noise in England. Transp Res Part D: Transp Environ 56:43-54

29. Grollman C, Martin I, Mhonda J (2020) Aviation noise and public health. Rapid evidence assessment. NatCen Social Research that works for society. Prepared for: The Independent Commission on Civil Aviation Noise (ICCAN)

30. Guski R, Felscher-Suhr U, Schuemer R (1999) The concept of noise annoyance: How international experts see it. J Sound Vib 223:513-527

31. Hartig T, Evans GW, Jamner LD, Davis DS, Gärling T (2003) Tracking restoration in natural and urban field settings. J Environ Psychol 23:109-123

32. Hartig T, Johansson G, Kylin C (2003) Residence in the social ecology of stress and restoration. J Soc Issues 59(3):611-636

33. Haubrich J, Benz S, Isermann U, Schäffer B, Schmid R, Schreckenberg D, Wunderli J-M, Guski R (2020) Leq+X_Lärmexposition, Ereignishäufigkeiten und Belästigung: Re-Analyse 
von Daten zur Belästigung und Schlafstörung durch Fluglärm an deutschen und Schweizer Flughäfen (Leq $+X-$ Noise exposure, number of events and annoyance: Re-analysis of aircraft noise annoyance and sleep disturbance data at German and Swiss Airports. Hauptbericht Bochum: Ruhr-Universität Bochum. https://doi.org/10.46586/rub.164.139

34. Haubrich J, Burtea NE, Flindell I, Hooper P, Hudson R, Rajé F, Schreckenberg D, et al (2019) ANIMA D2.4-Recommendations on annoyance mitigation and implications for communication and engagement. Zenodo. https://doi.org/10.5281/zenodo.3988131

35. Hiroe M, Makino K, Ogata S, Suzuki S (2017) A questionnaire survey on health effects of aircraft noise for residents living in the vicinity of Narita International Airport: the results of physical and mental health effects. In: Proceedings: ICBEN 2017. Zurich

36. Holt JB, Zhang X, Sizov N, Croft JB (2015) Airport noise and self-reported sleep insufficiency, United States, 2008 and 2009. Prev Chronic Dis 12:E49

37. Janssen SA, Centen MR, Vos H, van Kamp I (2014) The effect of the number of aircraft noise events on sleep quality. J Appl Acoust 84:9-16

38. Kim SJ, Chai SK, Lee KW, Park JB, Min KB, Kil HG (2014) Exposure-response relationship between aircraft noise and sleep quality: a community-based cross-sectional study Osong public health and research perspectives 5(2):108-114

39. Klatte M, Spilski J, Mayerl J, Möhler U, Lachmann T, Bergström K (2017) Effects of aircraft noise on reading and quality of life in primary school children in Germany: results from the NORAH study. Environ Dev 49(4):390-424

40. Koolhaas JM, Bartolomucci A, Buwalda B, de Boer SF, Flügge G, Korte SM et al (2011) Stress revisited: a critical evaluation of the stress concept. Neurosci Biobehav Rev 35:1291-1301

41. Kranjec N, Benz S, Burtea NE, Hooper P, Hudson R, Jeram S, Schreckenberg D et al (2019) ANIMA D2.3-Recommendations on noise and health. Zenodo. https://doi.org/10.5281/zen odo. 2562748

42. Kranjec N, Kuhlmann J, Benz S, Schreckenberg D, Rajé F, Hooper P, Jeram S (2021) Aircraft noise health impacts and limitations in the current research. In: Proceedings of the 13th ICBEN congress on noise as a public health problem. Stockholm, Sweden, 14-17 June 2021

43. Kwak KM, Ju YS, Kwon YJ, Chung YK, Kim BK, Kim H et al (2016) The effect of aircraft noise on sleep disturbance among the residents near a civilian airport: a cross-sectional study. Annals Occup Environ Med 28:38

44. Lawton R, Fujiwara D (2016) Living with aircraft noise: airport proximity, aviation noise and subjective wellbeing in England. Transp Res Part D: Transp Environ 42:104-118

45. Lazarus RS, Folkman S (1984) Stress, appraisal, and coping. Springer Publishing Company, New York

46. Miedema HM, Vos H (2003) Noise sensitivity and reactions to noise and other environmental conditions. J Acoust Soc Am 113(3):1492-1504. https://doi.org/10.1121/1.1547437

47. Müller U, Elmenhorst E-M, Mendolia F, Quehl J, Basner M, McGuire S, Aeschbach D (2017) A comparison of the effects of night time air traffic noise on sleep at Cologne/Bonn and Frankfurt Airport after the night flight ban. In: Proceedings of the 12th international congress on noise as a public health problem (ICBEN). 2017, ID 3726

48. Müller U, Elmenhorst E-M, Mendolia F, Quehl J, Basner M, McGuire S, Aeschbach D (2016) The NORAH-Sleep Study: effects of the night flight ban at Frankfurt airport. In: Proceedings of Inter-noise 2016. Hamburg, Germany, pp 7782-7786. ISBN 978-3-939296-11-9

49. Nassur A-M, Léger D, Lefèvre M, Elbaz M, Mietlicki F, Nguyen P, Ribeiro C, Sineau M, Laumon B, Evrard A-S (2019) The impact of aircraft noise exposure on objective parameters of sleep quality: results of the DEBATS study in France. Sleep Med 54:70-77

50. Nassur AM, Lefevre M, Laumon B, Leger D, Evrard AS (2017) Aircraft noise exposure and subjective sleep quality: the results of the DEBATS study in France. Behavioral sleep medicine 1-12. 46. Kageyama T, Yano T, Kuwano S, Sueoka S, Tachibana H

51. Nguyen TL, Nguyen TL, Yano T, Nishimura T, Sato T, Morinaga M, Yamada I (2017) The opening of a new terminal building and its influences on community response around Hanoi Noi Bai International airport: comparison between arrival and departure sides 
52. Perron S, Plante C, Ragettli MS, Kaiser DJ, Goudreau S, Smargiassi A (2016) Sleep disturbance from road traffic, railways, airplanes and from total environmental noise levels in Montreal. Int J Environ Res Public Health 13(8):809. https://doi.org/10.3390/ijerph13080809

53. Porter ND, Kershaw AD, Ollerhead JB (2000) Adverse effects of night-time aircraft noise (Rep. No. 9964). UK Civil Aviation Authority, London, UK

54. Pyko A, Eriksson C, Lind T, Mitkovskaya N, Wallas A, Ögren M, Östenson C, Pershagen G (2017) Long-term exposure to transportation noise in relation to development of obesity-a cohort study. Environ Health Perspect 125(11):117005

55. Rocha S, Smith MG, Witte M, Basner M (2019) Survey results of a pilot sleep study near Atlanta international airport. Int J Environ Res Public Health 16:4321

56. Rojek et al (2021) The relation of nocturnal exposure to aircraft noise and aircraft noise-induced insomnia with blood pressure

57. Röösli M, Vienneau D, Foraster M, Eze I, Héritier H, Schaffner E (2017) Short and long term effects of transportation noise exposure (SiRENE): an interdisciplinary approach. In: Proceedings: ICBEN 2017. Zurich

58. Saucy A, Schäffer B, Tangermann L, Vienneau D, Wunderli JM, Röösli M (2021) Does nighttime aircraft noise trigger mortality? A case-crossover study on 24886 cardiovascular deaths. Eur Heart J 42:835-843

59. Schmidt FP, Herzog J, Schnorbus B, Ostad MA, Lasetzki L, Hahad O, Schäfers G, Gori T, Sørensen M, Daiber A, Münzel T (2020) The impact of aircraft noise on vascular and cardiac function in relation to noise event number: a randomised trial. Cardiovasc Res 1-9. https://doi. org/10.1093/cvr/cvaa204

60. Schreckenberg D, Belke C, Faulbaum F, Guski R, Möhler U, Spilski J (2016) Effects of aircraft noise on annoyance and sleep disturbances before and after expansion of Frankfurt Airportresults of the NORAH study, WP1 'Annoyance and quality of life'. In: Proceedings: InterNoise 2016. Hamburg

61. Schreckenberg D, Benz S, Belke C, Möhler U, Guski R (2017) The relationship between aircraft sound levels, noise annoyance and mental well-being: An analysis of moderated mediation. In: Proceedings of the 12th ICBEN congress on noise as a public health problem. Zurich, Switzerland 18-22 June 2017. http://www.icben.org/2017/ICBEN\%202017\%20Papers/Subjec tArea03_Schreckenberg_0326_3635.pdf

62. Seidler A, Hegewald J, Seidler AL, Schubert M, Zeeb H (2019) Is the whole more than the sum of its parts? Health effects of different types of traffic noise combined. Int J Environ Res Public Health 16:1665. https://doi.org/10.3390/ijerph16091665

63. Smith MG, Rocha S, Witte M, Basner M (2020) On the feasibility of measuring physiologic and self-reported sleep disturbance by aircraft noise on a national scale: a pilot study around Atlanta airport. Sci Total Environ 718:137368

64. Spilski J, Rumberg M Berchterhold M, Bergström K, Möhler U, Kurth D, Lachmann T, Klatte M (2019) Effects of aircraft noise and living environment on children's wellbeing and health. In: Proceedings of the 23rd international congress on acoustics. Aachen, Germany

65. Stallen PJM (1999) A theoretical framework for environmental noise annoyance. Noise Health 3:69-79

66. Trieu BL, Nguyen TL, Bui TL (2019) Assessment of health effects of aircraft noise on residents living around Noi Bai International Airport. In: Madrid inter-noise conference 2019: noise control for a better environment. Madrid, Spain

67. van den Berg F, Verhagen C, Uitenbroek D (2014) The relation between scores on noise annoyance and noise disturbed sleep in a public health survey. Int J Environ Res Public Health 11(2):2314-2327

68. van Kamp I, Davies H (2013) Noise and health in vulnerable groups: a review. Noise Health 15(64):153-159. https://doi.org/10.4103/1463-1741.112361

69. van Kamp I, Davies H (2008) Environmental noise and mental health: five year review and future directions. In: Proceedings of the 9th ICBEN congress on noise as a public health problem. Mashantucket, Connecticut, U.S.A. 
70. Van Kamp I, van Kempen EEMM, Simon SN, Baliatsas C (2019) Review of the evidence relating to environmental noise exposure and annoyance, sleep disturbance, cardio-vascular and metabolic health outcomes in the context of ICGB (N), RIVM Report 2019-0088 institute for public health and the environment (RIVM). Bilthoven, The Netherlands. https://doi.org/10. 21945/RIVM-2019-0088

71. van Kamp I, Job SRF, Hatfield J, Haines M, Stellato RK, Stansfeld SA (2004) The role of noise sensitivity in the noise-response relation: a comparison of three international airport studies 2004. J Acoust Soc Am 116:3471-3479

72. Van Poll R, Ameling C, Breugelmans O, Houthuijs D, van Kempen E, Marra M, Swart W (2014) Gezondheidsonderzoek Vliegbasis Geilenkirchen (Desk Research) I. Hoofdrapportage: Samenvatting, Conclusies en Aanbevelingen Gezondheidsonderzoek Vliegbasis Geilenkirchen; National Institute for Public Health and the Environment: Bilthoven, The Netherlands (In Dutch)

73. Von Lindern E, Hartig T, Lercher P (2014) Assessing the relationship between perceived disturbances from traffic, restorative qualities of the living environment, and health. In: Proceedings of the 43rd international congress on noise control. Melbourne, Australia, 16-19 Nov 2014

74. Von Lindern E, Hartig T, Lercher P (2016) Traffic-related exposures, constrained restoration, and health in the residential context. Health Place 39:92-100. https://doi.org/10.1016/j.health place.2015.12.003

75. World Health Organisation (2011) Burden of disease from environmental noise. Quantification of healthy life years lost in Europe. WHO Regional Office for Europe, Copenhagen

76. World Health Organisation Regional Office for Europe (2018) WHO environmental noise guidelines for the European region. Copenhagen, Denmark: World Health Organisation, WHO Regional Office for Europe

77. Zeeb H, Hegewald J, Schubert M, Wagner M, Dröge P, Swart E, Seidler A (2017) Traffic noise and hypertension—results from a large case-control study. Environ Res 157:110-117

Open Access This chapter is licensed under the terms of the Creative Commons Attribution 4.0 International License (http://creativecommons.org/licenses/by/4.0/), which permits use, sharing, adaptation, distribution and reproduction in any medium or format, as long as you give appropriate credit to the original author(s) and the source, provide a link to the Creative Commons license and indicate if changes were made.

The images or other third party material in this chapter are included in the chapter's Creative Commons license, unless indicated otherwise in a credit line to the material. If material is not included in the chapter's Creative Commons license and your intended use is not permitted by statutory regulation or exceeds the permitted use, you will need to obtain permission directly from the copyright holder.

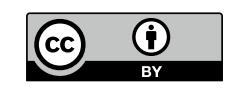

